\section{Physics in Industry in the United States}

THe Advisory Council on Applied Physics of the American Institute of Physics met at the University Club, Pittsburgh, Pa., on November 16. This was the inaugural meeting of this Council, the purpose of which is to stimulate the application of physics by recommending suitable actions and policies to the Institute and the founder societies. Dr. Paul D. Foote, executive vice-president of the Gulf Research and Development Corporation, presided during the morning session and Dr. Lyman J. Briggs, director of the Bureau of Standards, during the afternoon. A discussion was held on the university education and training of men whose careers are to lie in industrial research. This discussion was opened with reports by Dr. Saul Dushman (presented by Dr. A. W. Hull) of the General Electric Co. and Prof. George H. Harrison of the Massachusetts Institute of Technology. Further discussion was devoted to the services which are rendered by the founder societies and the Institute to physicists employed in industrial laboratories. Reports on this topic were presented by Dr. L. O. Grondahl, director of research, Union Switch and Signal Co., and Prof. John T. Tate, of the University of Minnesota. In this connexion, the Council passed a resolution encouraging the formation by such physicists of a division on applied physics of the Physical Society. It is strongly felt that, while the Optical Society, the Acoustical Society and the Society of Rheology furnish splendid facilities for meetings and publications in their fields, other general applications of physics are neglected. The opinion of the Council is opposed to the formation of new specialised societies, since only through close integration with the Physical Society can the community of interest and interchange of ideas between the general applications and the basic fundamentals of physics be conserved.

\section{South Indian Bronzes at South Kensington}

Bronze figures of the members of the Hindu Pantheon in their various manifestations are a conspicuous feature in the art of southern India. Of these, there is a large collection in the Madras Government Museum, which is perhaps not so widely known in detail as it deserves. The iconographic value of these bronzes is great : they are an important source of information for Hindu religious and cosmological conceptions; but, as a rule, their artistic merit is not high. It is now announced that, by a bequest of the late Lord Ampthill, formerly Governor of the Madras Presidency, the Victoria and Albert Museum, South Kensington, has acquired five of these bronzes, which are both of high artistic merit and of interest for their religious significance. Of these the most important is a figure of Siva as the Cosmic Dancer, which expresses the idea that the god himself is both performer and audience, while the universe is his theatre. The figure is four-armed, and appears in a dancing attitude in an encircling flaming nimbus. In its upper hands are a drum and fire as the symbols of creation and destruction respectively, while the lower hands are in the conventional attitudes of protection and assuranee. The headdress includes a crescent moon, a human skull, cobras and flowers. The male and female principles are signified by a man's ear-ring in the right ear and a woman's ear-ring in the left ear. With this figure is shown one of his consort Parvati, in the manifestation of Gauri. These figures were found buried near a temple in the Tinevally District of the Madras Presidency. They were made by the cire perdue process; and from their stylistic affinities it is concluded that they belong to the late tenth or early eleventh century of our era. Lord Ampthill's bequest, part of which had previously been on loan in the museum, includes, in addition to the five bronzes, a number of other objects of great interest, illustrative of Brahmanical and Buddhist beliefs.

\section{Vision in Optical Instruments}

IN his Thomas Young Oration of the Physical Society on December 6, Prof. Charles Fabry discussed "Vision in Optical Instruments". Classical theory gives the resolving power of an optical instrument as determined by diffraction phenomena, but the result so obtained takes no account of the properties of the eye. Consequently, it does not indicate exactly what will actually be perceived with an instrument. What can actually be seen with such an instrument depends considerably on the brightness of the object examined, and on the degree of contrast between its parts and between the object and the background. In order to examine these questions, it is necessary to commence with the properties of the eye, and in particular, its ability to distinguish objects, not under the ideal conditions reached in the laboratory, but under conditions similar to those met with during observations. The effect of brightness is particularly large : for the greatest brightness the limit of resolution is about $\mathbf{l}^{\prime}$, whilst it is 250 times as large (about $4^{\circ}$ ) for barely perceptible brightness. Contrast also has a very large effect. With these data, it becomes possible to determine what the eye will really see in a given instrument, assumed to be of perfect geometrical construction. The optimum size of exit-pupil can be calculated, and is found to be $0.7 \mathrm{~mm}$. for the highest illumination, in agreement with experience. For an instrument with geometrical imperfections, an efficiency can be defined characterising the qualities of this instrument as compared with those of a perfect instrument. Stray light (fog) is another cause of inferiority in instruments, and the effect of this factor was discussed by Prof. Fabry.

\section{Automatic Fire and Burglar Alarms}

A Device, invented in France, which can be used either as a fire alarm which will give automatically a telephone message to the fire brigade, or as a burglar alarm which will summon the police, is described in The Times of December 7. The apparatus is called a 'signaphone', and is already installed in about forty buildings in Paris. When used as a fire alarm, the device is operated either by thermostats fixed near the ceiling, or by push buttons so that a watchman has only to press the nearest button. The thermostats are operated by hot air rising to the 